This manuscript was accepted and published by Industrial \& Engineering Chemistry Research, a journal of the American Chemical Society.

Publication data of the final, corrected work:

Várhegyi, G.; Mészáros, E.; Antal, M. J., Jr.; Bourke, J.; Jakab, E.: Combustion

kinetics of corncob charcoal and partially demineralized corncob charcoal in the

kinetic regime. Ind. Eng. Chem. Res. 2006, 45, 4962-4970. doi: $10.1021 / \mathrm{ie} 0602411$

\title{
Combustion Kinetics of Corncob Charcoal and Partially Demineralized Corncob Charcoal in the Kinetic Regime
}

\author{
Gábor Várhegyi ${ }^{* *}$,Erika Mészáros ${ }^{\dagger}$, Michael J. Antal*, Jr., Jared Bourke ${ }^{\ddagger}$, Emma Jakab ${ }^{\dagger}$ \\ ${ }^{\dagger}$ Hungarian Academy of Science, Chemical Research Center, Institute of Materials and Environmental \\ Chemistry, P. O. Box 17, Budapest 1525 , Hungary and $\$$ Hawaii Natural Energy Institute, School of Ocean \\ and Earth Science and Technology, University of Hawaii at Manoa, Honolulu, Hawaii 96822.
}

\footnotetext{
*Corresponding author. Email: varhegyi.gabor@t-online.hu or gvarhegyi@gmail.com

$\S$ Present affiliation: The University of Waikato, New Zealand.
}

\begin{abstract}
Charcoals produced by a modern, efficient method were studied in the kinetic regime, at oxygen partial pressures of 0.2 and 1 bar by thermogravimetric experiments and their reaction kinetic modeling. The charcoals were ground to an average particle size of $5-13 \mu \mathrm{m}$. A partial removal of minerals from the feedstock (corncobs) by an acid-washing procedure resulted in ca. 6 times higher specific surface area in the charcoal. In spite of the increased surface area, this sample evidenced a much lower reactivity. A model based on three reactions gave an adequate description over a wide range of experimental conditions. 38 experiments on 4 charcoal samples were evaluated. The experiments differed in their temperature programs, in the ambient gas composition and in the grinding of the samples. Characteristics of the combustion process were determined, including activation energy values characteristic for the temperature dependence of the burn-off; formal reaction orders characterizing the dependence on the oxygen content of the ambient; and functions describing the conversion dependence of the partial processes.
\end{abstract}

KEYWORDS: Biomass, char, charcoal, kinetics, thermogravimetry. 
Várhegyi et al., Combustion kinetics of corncob charcoals, Page 2 of 19

\section{Introduction}

In his original patent Rudolph Diesel described the use of powdered coal as a fuel for the compressionignition engine. Diesel soon abandoned this idea in favor of liquid fuels; nevertheless research concerning the behavior of coal fuels in diesel engines continued in Germany until the end of World War II. ${ }^{1-3}$ Interest in this topic revived during the "energy crisis" of the 1970's. The U.S. Department of Energy sponsored two 5year proof-of-concept projects and related research involving both coal-water slurries ${ }^{4}$ and dry coal powder fuel tests in diesel engines, and the development of numerical models for simulating the behavior of coalfired diesel engines. ${ }^{5}$ These projects identified the following problems associated with coal fueled diesel engines: engine component durability (i.e. injector nozzle wear), emissions, and carbon combustion efficiency.

Likewise research has been directed towards the development of coal-fired gas turbines. Recently a consortium of Japanese companies (including Mitsubishi Heavy Industries, Idemitsu Kosan Co., Kyushu Electric Power Co. and the Japanese Center for Coal Utilization) tested an ultra-clean coal produced by Australian companies (UCC Energy Pty Ltd., Clark Services Australia Pty Ltd., and CSIRO). ${ }^{6}$ In spite of their use of Australian ultra-clean coal, problems were encountered with emissions (i.e. $\mathrm{NO}_{\mathrm{x}}$ and $\mathrm{SO}_{\mathrm{x}}$ ), ash deposition on the turbine blades, and carbon combustion efficiency.

As contrasted with coals, renewable biocarbons (i.e. charcoal) have very low ash, nitrogen and sulfur contents. $^{7,8}$ Moreover, because of their pore structure and the presence of dangling bonds, biocarbons are much more reactive than fossil carbons. ${ }^{8}$ Consequently, we believe that biocarbons could be good fuels for both diesel engine and gas turbine applications. The recent discovery ${ }^{9}$ of an efficient method for producing biocarbon from virtually any biomass feedstock gives additional impetus to an examination of the use of biocarbons as a fuel for diesel engines and gas turbines. Unfortunately, little is known of the combustion kinetics of charcoal in air at elevated pressures. Information of this sort is needed to establish favorable operating conditions for charcoal-fired diesel engines and gas turbines. In this paper we present measurements of the rates of corncob charcoal combustion in the presence of oxygen with partial pressures of 0.2 and 1 bar. We study the burn-off behavior of the chars and its variation with various factors by the evaluation and modeling of a large number of thermogravimetric experiments within a wide range of experimental conditions, in the kinetic regime.

\section{Experimental}

2.1. Charcoal preparation. Corncob obtained from Waimanalo, Oahu, Hawaii was used as feed material $^{10}$ for the Flash Carbonization ${ }^{\mathrm{TM}}$ (FC) process at an elevated pressure of 1.4 MPa. Further details on the procedure can be found in a recent publication ${ }^{10}$. Proximate analysis results indicate differences in charcoal properties according to the original position of the feed within the lab-scale reactor canister. (See Table 1.) The 'top' portion of corncob charcoal has lower volatile matter content than the 'middle' and 'bottom' portions. This physical property indicates a higher temperature being present for a longer period of time at the top of the reactor canister. The 'top' portion of corncob charcoal also has an increased ash content compared to the 'middle' and 'bottom' portions. The concentration of ash present in charcoal is influenced by 
the degree of carbonization. The 'middle' portion of corncob charcoal has the highest volatile matter content indicating that lower carbonization temperatures were reached in this section of the canister.

2.2. Partial Demineralization of Chopped Corncob. The removal of extraneous minerals from corncob biomass was achieved by employing a hot citric acid wash. Corncobs were broken up into smaller pieces typically $2-3 \mathrm{~cm}$ in length by $1 \mathrm{~cm}$ in diameter. The chopped corncob was left out in ambient laboratory conditions for a 24 -hour period. $750 \mathrm{~g}$ air-dry corncob was washed by $7 \mathrm{~L}$ of $0.1 \mathrm{~mol} / \mathrm{L}$ citric acid solution for 2 hours at about $90^{\circ} \mathrm{C}$. The acid wash was followed by a room-temperature washing in deionized water. After drying, charcoal was produced by the FC procedure described above.

The 'middle' portion of the partially demineralized cob charcoal was used for the present studies. Its volatile matter content is close to the 'middle' portion of the untreated corncob charcoal. The ash content of the demineralized cob charcoal is lower than any of the untreated corncob charcoal portions. This indicates that part of the inorganic minerals was successfully leached from the biomass via the hot citric acid pretreatment. The specific surface area of demineralized corncob charcoal is higher $\left(58 \mathrm{~m}^{2} / \mathrm{g}\right)$ than that of the untreated corncob charcoal with comparable volatile matter content $\left(9 \mathrm{~m}^{2} / \mathrm{g}\right)$.

Table 1. Proximate analysis of the samples

\begin{tabular}{lllccc}
\hline Feed & Section $^{\mathrm{a}}$ & $\begin{array}{l}\text { Abbrevi- } \\
\text { ation }\end{array}$ & \multicolumn{3}{c}{ Proximate } \\
\cline { 4 - 6 } & & Analysis & VM & fC & ash \\
\hline Corncob & Top & Top & 6.9 & 90.7 & 2.4 \\
& Middle & Mid & 18.8 & 79.9 & 1.3 \\
& Bottom & Bot & 13.7 & 84.6 & 1.7 \\
Partially & Middle & Dem & 19.8 & 79.4 & 0.9 \\
demineralized & & & & & \\
corncob & & & & & \\
\hline
\end{tabular}

${ }^{a}$ Refers to the position of the charcoal within the lab-scale flash carbonization canister. ${ }^{b}$ Dry Basis - ASTM D1762-84 (Reapproved 1990).

2.3. Grinding. The charcoals were ground by a Fritsch-Pulverisette 6 ball mill, in hermetically sealed corundum vessels with corundum grinding balls. The resulting particle size distribution was measured by a Malvern 2600C laser diffraction particle size analyzer. A milder grinding to an average particle size of 9$11 \mu \mathrm{m}$ was carried out by a rotation rate of $200 \mathrm{~min}^{-1}$ with a residence time of $20 \mathrm{~min}$. A stronger grinding to an average particle size of $5-6 \mu \mathrm{m}$ was achieved by doubling the rotation rate and increasing the residence time to 2 sections of 30 min (with a pause between them for cooling). For the middle section sample a 10 min grinding was also carried out at this speed. In the present paper the grinding will be indicated by the average particle size for each sample. The partially demineralized char was ground by the milder process and was also studied with larger grains obtained by grinding in a bench top Wiley mill and sieving to a particle

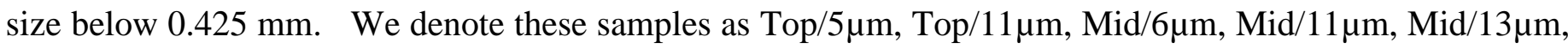
Bot $/ 5 \mu \mathrm{m}$, Bot $/ 11 \mu \mathrm{m}, \mathrm{Dem} / 9 \mu \mathrm{m}$, and Dem $<425 \mu \mathrm{m}$, respectively. 
Várhegyi et al., Combustion kinetics of corncob charcoals, Page 4 of 19

2.4. Thermogravimetric experiments. A computerized Perkin-Elmer TGS-2 thermobalance was employed. $20 \mathrm{~V} / \mathrm{V} \%$ oxygen-nitrogen mixture and pure oxygen were used as purge gas with a gas flow of $140 \mathrm{ml} / \mathrm{min}$. Low sample masses were employed due to the huge reaction heat of combustion. The proper values were based on earlier experience with the same instrument ${ }^{11-14}$ and on actual test experiments. Note that the highest reaction rate in an experiment is roughly proportional to the sample mass and the heating rate in the kinetic regime in addition to being obviously dependent on the reactivity of the given sample and on the oxygen partial pressure. If the reaction rate is too high, the heat release results in an accelerating selfheating (ignition). The temperature inside the sample becomes considerably higher than the value prescribed by the temperature program and the sample burns-off at a high reaction rate. An example is shown in Figure 1.

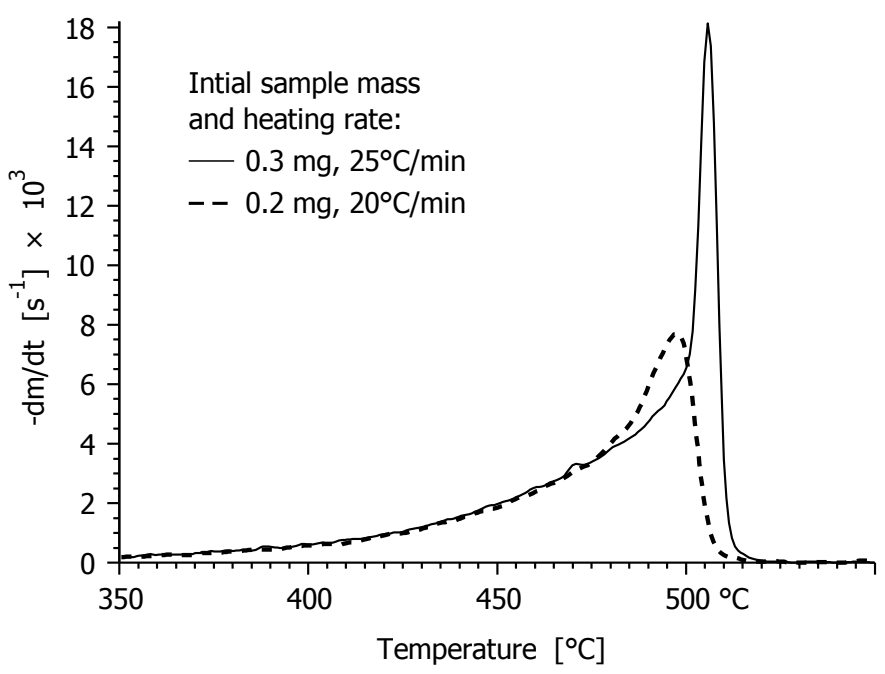

Figure 1. Example for experiments with (-) and without (- -) a considerable self-heating in $20 \%$

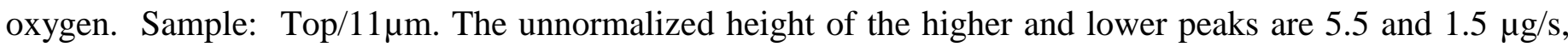
respectively. (The experiments revealing self-heating were not used for the kinetic evaluation.)

In the linear heating rate experiments $0.2-0.6 \mathrm{mg}$ sample masses were employed, depending on the heating rate, oxygen concentration and the reactivity of the given sample. The experimental repeatability at such low sample masses have been discussed earlier ${ }^{13}$. The buoyancy effect was corrected by subtracting the TG signal of similar experiments with empty sample holders. The information content of the experimental series was increased by including stepwise temperature programs ${ }^{11-14}$. The stepwise temperature programs were composed from linearly increasing and isothermal sections; the heating rate in the increasing sections was $10^{\circ} \mathrm{C} / \mathrm{min}$. The choice of the isothermal temperatures was influenced by the reactivity of the samples. When low reactivity was observed, the isothermal temperatures were slightly increased to ensure a measurable signal in all isothermal steps. The decomposition of the partially demineralized samples occurred in a wider temperature domain, allowing a larger number of isothermal steps. Table 2 lists the 38 experiments used for the kinetic evaluation. 
Table 2. Temperature programs employed

\begin{tabular}{|c|c|c|c|}
\hline $\begin{array}{l}\text { Heating } \\
\text { rate } \\
\left({ }^{\circ} \mathrm{C} / \mathrm{min}\right)\end{array}$ & $\begin{array}{l}\mathrm{O}_{2} \text { in gas } \\
\text { phase } \\
(\% \mathrm{~V} / \mathrm{V})\end{array}$ & $\begin{array}{l}\text { Temperature of isothermal } \\
\text { sections }^{\mathrm{a}}\end{array}$ & Samples subjected to the program \\
\hline 5 & 100 & - & All samples \\
\hline 20 & 20 & - & $\begin{array}{l}\text { Top } / 11 \mu \mathrm{m}, \mathrm{Mid} / 13 \mu \mathrm{m}, \text { Bot } / 11 \mu \mathrm{m} \text {, } \\
\text { Dem } / 9 \mu \mathrm{m}, \text { Dem }<425 \mu \mathrm{m}\end{array}$ \\
\hline 25 & 20 & - & $\begin{array}{l}\text { Top } / 5 \mu \mathrm{m}, \mathrm{Mid} / 6 \mu \mathrm{m}, \mathrm{Mid} / 11 \mu \mathrm{m} \text {, } \\
\text { Bot } / 5 \mu \mathrm{m}\end{array}$ \\
\hline 10 & 20,100 & $300,330,360^{\mathrm{b}}$ & $\begin{array}{l}\text { Top } / 5 \mu \mathrm{m}, \mathrm{Mid} / 6 \mu \mathrm{m}, \mathrm{Mid} / 11 \mu \mathrm{m} \text {, } \\
\text { Bot } / 5 \mu \mathrm{m},\end{array}$ \\
\hline 10 & 20,100 & $310,340,370^{b}$ & Top/11 $\mu \mathrm{m}, \mathrm{Mid} / 13 \mu \mathrm{m}, \mathrm{Bot} / 11 \mu \mathrm{m}$ \\
\hline 10 & 100 & $310,340,370,400$ & $\operatorname{Dem} / 9 \mu \mathrm{m}$ \\
\hline 10 & 20,100 & $310,340,370,400,430$ & $\operatorname{Dem} / 9 \mu \mathrm{m}, \mathrm{Dem}<425 \mu \mathrm{m}$ \\
\hline 10 & 20 & $310,340,370,400,430,460$ & $\operatorname{Dem} / 9 \mu \mathrm{m}$ \\
\hline
\end{tabular}

${ }^{\mathrm{a}}$ The usual duration of an isothermal step was $30 \mathrm{~min} .{ }^{\mathrm{b}} 60-120 \mathrm{~min}$

\section{The Mathematical Model}

3.1. A brief review of earlier work. Thermal analysis has proved to be a suitable tool for studying the combustion properties of charcoals and other chars in the kinetic regime. ${ }^{11-12,14-18}$ Shafizadeh and Sekiguchi ${ }^{15}$ have examined the smoldering combustion of cellulosic chars and observed distinct stages for the oxidation of the aliphatic and aromatic components. Janse et al. ${ }^{16}$ described the combustion kinetics of wood chars by assuming a 1-step burn-off process. With a slightly different notation, their basic equation can be written as

$$
\mathrm{d} \alpha / \mathrm{dt}=\mathrm{A}_{\mathrm{q}} \exp (-\mathrm{E} / \mathrm{RT}) \frac{s(\alpha)}{s_{0}} \mathrm{P}_{\mathrm{O}_{2}}{ }^{\mathrm{q}}
$$

where $\alpha$ is the fractional burn-off, $\mathrm{s}$ is the active reaction surface, $\mathrm{s}_{0}$ is its initial value, $\mathrm{P}_{\mathrm{O}_{2}}$ is the partial pressure of oxygen, $\mathrm{q}$ is a formal reaction order. (See the "Nomenclature" section, too, for symbols and subscripts.) This equation was found to be valid above $375^{\circ} \mathrm{C}$. They tested several pore development models for $\mathrm{s}(\alpha)$ and observed that the best fit could be obtained by a simple, empirical formula:

$$
\mathrm{s}(\alpha) / \mathrm{s}_{0} \cong(1-\alpha)^{\mathrm{b}}
$$

where $b$ is an empirical constant determined from the kinetic evaluation of the experiments. Janse et al. ${ }^{16}$ have also analyzed the necessary experimental conditions and showed that low sample masses (in their case $0.3-0.4 \mathrm{mg}$ ) had to be employed in thermogravimetric experiments to avoid the self heating of the samples during the experiments. Di Blasi et al. ${ }^{17}$ analyzed a wide range of biomass chars by similar one step global models. Várhegyi et al. ${ }^{14}$ described the combustion of high-yield biomass chars by two consecutive reactions, where the 1 st reaction corresponded to devolatilization and the 2 nd reaction described the burn-off of the devolatilized chars. In a later work ${ }^{18}$, Branca and Di Blasi employed 3 parallel reactions to describe the combustion of wood chars. The 1 st and 2 nd reactions referred to devolatilization steps while the 3rd reaction described the char burn-off. The devolatilization steps were assumed to be simple 1st order reactions independent of the oxygen concentration: 
$\mathrm{d} \alpha_{\mathrm{j}} / \mathrm{dt}=\mathrm{A}_{\mathrm{j}} \exp \left(-\mathrm{E}_{\mathrm{j}} / \mathrm{RT}\right)\left(1-\alpha_{\mathrm{j}}\right)$

where $\mathrm{j}=1$ and 2 and $\alpha_{\mathrm{j}}$ is the reacted fraction of the volatiles released in reaction $j$. The char burn-off reaction was described similarly to equations (1) - (2).

3.2. Kinetic equations for the present work. In the case of ideal chars (i.e. specially prepared, pure model carbons) the reaction rate is proportional to the surface area, and the change of the surface area during the reaction can be described by theoretical models. ${ }^{19-22}$ In case of real chars, however, complicating factors arise: (i) the accessibility of the internal pores, including the opening of closed pores; (ii) the role of the inorganic catalysts; (iii) the chemical/physical inhomogeneity of the carbon phase. Accordingly, the dependence of the reaction rate on the burn-off cannot be interpreted as the change of an active surface alone. Besides, the inhomogeneity of the samples and the onset of additional reactions may require the inclusion of more than one reaction kinetic equations for the burn-off process. ${ }^{11}$ One should also consider that the dimension of preexponential factor $A_{q}$ in eq. 1 is $\mathrm{s}^{-1} \mathrm{kPa}^{-q}$, where $q$ is the reaction order on $P_{O_{2}}$. It is a usual requirement that the dimensions of a model should be constants. Since all experiments of the present work were carried out at atmospheric pressure, the preexponential factors also belong to atmospheric pressure. Accordingly, we can use the relative oxygen concentration, $\mathrm{C}_{2}(\mathrm{~V} / \mathrm{V})$, which is a dimensionless quantity running from 0 to 1 .

Let us assume $\mathrm{M}$ partial reactions. As an approximation, let us assume that the partial reactions are independent of each other. Let $\alpha_{j}$ be a reacted fraction that describes the conversion of the portion of charcoal belonging to the given partial reaction. ${ }^{11,13,18}$ This procedure means that the charcoal is regarded as a sum of pseudocomponents, where the term pseudocomponent indicates a fraction differing from the other fractions by its reactivity. The kinetic equations are written in the form

$$
\mathrm{d} \alpha_{j} / \mathrm{d} t=A_{j} \exp \left(-E_{j} / R T\right) f_{j}\left(\alpha_{j}\right) \mathrm{CO}_{2}{ }^{q}
$$

where $f_{j}\left(\alpha_{j}\right)$ is an empirical function describing the dependence of the reaction rate on the reacted fraction. Note that all $f_{j}\left(\alpha_{j}\right)$ functions differing only in constant multipliers are equivalent in eq. 1 since parameter $A_{j}$ can compensate any multipliers in $f_{j}\left(\alpha_{j}\right)$. Accordingly, the mathematical unambiguity requires normalizing for $f_{j}\left(\alpha_{j}\right)$. We use

$$
\max f_{j}\left(\alpha_{j}\right)=1
$$

for normalizing. ${ }^{11}$ The following empirical formula has proved useful for the description of char reactivity ${ }^{11,12}$ as well as other reactions ${ }^{23}$ :

$$
f_{j}\left(\alpha_{j}\right)=\text { normfactor }\left(\alpha_{j}+z_{j}\right)^{\mathrm{a}_{\mathrm{j}}}\left(1-\alpha_{j}\right)^{\mathrm{b}_{\mathrm{j}}}
$$

where $a_{j}, b_{j}$ and $z_{j}$ are formal parameters determining the shape of $f_{j}\left(\alpha_{j}\right)$ and the normalizing factor, normfactor, serves to satisfy eq. 5. The normalizing factor is a simple function of $a_{j}, b_{j}$ and $z_{j} .{ }^{11}$ Formula 6 describes the dependence on the reacted fraction on a wide variety of $f_{j}\left(\alpha_{j}\right)$ differing in shape, acceleration, peak position, etc. ${ }^{23}$ If $a_{j}=0$, formula 6 is identical with a formal reaction order model. ${ }^{14,17-18}$ When $a_{j} \neq 0$, $f_{j}(0)=$ normfactor $z_{j}{ }^{{ }_{j}}$. 
In this model, the overall reaction rate is a linear combination of the rates of the partial processes:

$$
-\mathrm{dm} / \mathrm{dt}=\sum_{j=1}^{M} c_{j} d \alpha_{j} / d t
$$

where $\mathrm{m}(\mathrm{t})$ is the sample mass divided by the initial sample mass. The unknown parameters of the model are determined by the method of least squares employed on a series of experiments by minimizing the following sum:

$$
S=\sum_{k=1}^{N_{\text {exp }}} \sum_{i=1}^{N_{k}} \frac{\left[\left(\frac{d m}{d t}\right)_{k}^{o b s}\left(t_{i}\right)-\left(\frac{d m}{d t}\right)_{k}^{c a l c}\left(t_{i}\right)\right]^{2}}{N_{k} h_{k}^{2}}
$$

Subscript $k$ indicates the experiments differing in grinding, oxygen partial pressure or heating program. $N_{\exp }$ is the number of experiments evaluated simultaneously, $t_{i}$ denotes the time values in which the digitized $(\mathrm{d} m / \mathrm{d} t)^{\text {obs }}$ values were taken, and $N_{k}$ is the number of the $t_{i}$ points in a given experiment. $h_{k}$ denotes the heights of the evaluated curves that strongly depend on the experimental conditions. The division by $h_{k}{ }^{2}$ serves for normalization. The obtained fit was characterized by the following quantity:

$$
\text { fit }(\%)=100 \mathrm{~S}^{0.5}
$$

Eq. 9 is also employed to express the fit of a subgroup within the evaluated experiments. In such cases $\mathrm{S}$ is written for the given subgroup. A subgroup may be a single experiment, too.

\section{Results and discussion}

4.1 Evaluation of series of experiments. There are several ways for evaluating series of experiments by the method of least squares, as was discussed earlier. ${ }^{12,23}$ Among others, one has to determine: what parameters are common in the given set of experiments and what parameters depend on the experimental conditions. In the present work we found that the following considerations are suitable for the modeling and evaluation of our data:

(i) All experiments on a given type of charcoal were evaluated simultaneously. As described in the experimental, the experiments differed in the mean particle size; in the oxygen content of the ambient gas flow and in the temperature programs. This means the simultaneous evaluation of $8-12$ experiments for a sample.

(ii) The experiments could be described by the assumption of three partial reactions. The first reaction, in the lower part of the temperature range, was attributed to devolatilization, while the $2^{\text {nd }}$ and $3^{\text {rd }}$ reaction described the burn-off. Evaluations with the assumption of only one or two partial reactions did not provide satisfying results.

(iii) The dependence of the devolatilization step on the oxygen concentration was also studied since oxygen usually participates in the chemical reactions under the experimental conditions of the present study. A low, flat partial peak was attributed to this reaction. (See Figure 2.) This peak was highly overlapped by the more dominant char burn-off reactions, accordingly there was not enough information for the detailed study of the 
devolatilization. As a compromise, its dependence on the conversion was approximated by a simple $1^{\text {st }}$ order reaction, $f_{1}\left(\alpha_{1}\right)=\left(1-\alpha_{1}\right)$. In the given model it means setting $a_{1}$ to 0 and $b_{1}$ to 1 .

(iv) The burn-off of the untreated charcoals was found to be influenced by the level of grinding. (The grinding may influence the external surface area of the particles and the accessibility of the internal pores.) Accordingly, the parameters of the corresponding $\mathrm{f}_{2}\left(\alpha_{2}\right)$ and $\mathrm{f}_{3}\left(\alpha_{3}\right)$ functions were allowed to depend on the degree of grinding. As mentioned earlier, the $f_{j}\left(\alpha_{j}\right)$ functions are normalized to avoid mathematical ambiguity. All factors of the magnitude of the reaction rate merge formally into the preexponential factor in eq. 4. In this way, the preexponential factors of eq. 4 should also depend on the degree of grinding.
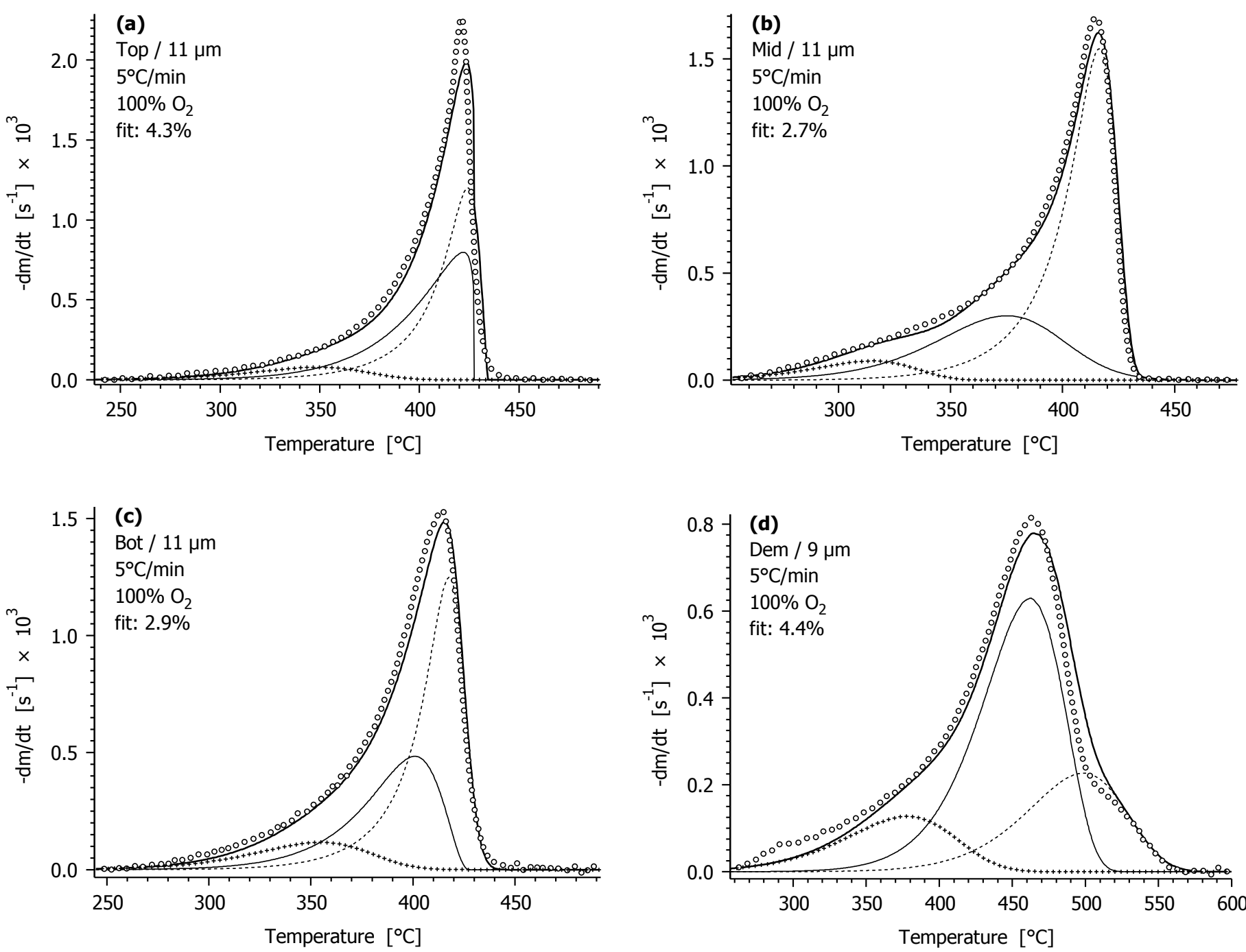

Figure 2. Experimental curves (o o o), simulated curves (-) and partial curves $(+++,-, \ldots, \ldots)$ belonging to $100 \% \mathrm{O}_{2}$ and $5^{\circ} \mathrm{C} / \mathrm{min}$ heating rate. The fit values shown were calculated separately for each experiment displayed. Partial curve ++++ is due to devolatilization. Partial curves $\_$and $\ldots$ describe burn-off processes.

Summarizing the above considerations, parameters $E_{j}, q_{j}$ and $c_{j}$ are assumed to be independent from the experimental conditions. The rest of the parameters, $A_{j}, a_{j}, b_{j}$ and $z_{j}$ are assumed to depend on the grinding. There was an exception, however: the burn-off of the partially demineralized charcoal did not show any 
dependence on the grinding in our experiments. Another exception was outlined earlier: all $f_{l}\left(\alpha_{1}\right)$ were approximated by a first order term. Table 3 gives a brief overview on the number of evaluated experiments and unknown parameters.

Table 3. The number of experiments and unknown parameters in the kinetic evaluation

\begin{tabular}{|c|c|c|c|c|}
\hline Sample & Top & Mid & Bot & Dem \\
\hline Grinding levels & 2 & 3 & 2 & 2 \\
\hline $\begin{array}{l}\text { Experiments with } \\
\text { linear } \mathrm{T}(\mathrm{t})\end{array}$ & 4 & 6 & 4 & 4 \\
\hline $\begin{array}{l}\text { Experiments with } \\
\text { stepwise } T(t)\end{array}$ & 4 & 6 & 4 & 6 \\
\hline $\begin{array}{l}\text { Unknown } \\
\text { parameters }\end{array}$ & 27 & 36 & 27 & 18 \\
\hline $\begin{array}{l}\text { Unknown } \\
\text { parameters per } \\
\text { experiment }^{\mathrm{a}}\end{array}$ & 3.4 & 3 & 3.4 & 1.8 \\
\hline
\end{tabular}

${ }^{a}$ The number of unknown parameters divided by the number of experiments in the given group.

4.2 The kinetic parameters and their discussion. The obtained parameters are listed in Table 4. As was outlined above, the meaning of the $\mathrm{a}, \mathrm{b}$ and $\mathrm{z}$ parameters lie in the shape of the corresponding $\mathrm{f}_{\mathrm{j}}\left(\alpha_{\mathrm{j}}\right)$ functions, accordingly two characteristics of the $f_{j}\left(\alpha_{j}\right)$ functions, $f_{j}(0)$ and the position of the maximum of $f_{j}\left(\alpha_{j}\right)$ functions, $\alpha_{\max , j}$, are also listed. Note that $\mathrm{a}_{\mathrm{j}}=0$ leads to undefined $\mathrm{z}_{\mathrm{j}}, \mathrm{f}_{\mathrm{j}}(0)=1$ and $\alpha_{\mathrm{max}, \mathrm{j}}=0$. (See eq. 6.). Since $f_{1}\left(\alpha_{1}\right)$ was assumed to be $1-\alpha_{1}$, the corresponding parameter values are not listed. 
Várhegyi et al., Combustion kinetics of corncob charcoals, Page 10 of 19

Table 4. The obtained kinetic parameters ${ }^{a}$ and the characteristics of the $f_{j}\left(\alpha_{j}\right)$ curves $^{b}$

\begin{tabular}{|c|c|c|c|c|c|c|c|c|}
\hline Sample & Top & Top & Mid & Mid & Mid & Bot & Bot & Dem $^{c}$ \\
\hline $\begin{array}{l}\text { Av. particle } \\
\text { size / } \mu \mathrm{m}\end{array}$ & 5 & 11 & 6 & 11 & 13 & 5 & 11 & $9-425$ \\
\hline Fit $^{\mathbf{d}} / \%$ & 4.4 & 3.6 & 3.7 & 2.7 & 1.8 & 4.2 & 2.5 & 4.0 \\
\hline $\mathrm{E}_{1} / \mathrm{kJ} \mathrm{mol}^{-1}$ & \multicolumn{2}{|c|}{108} & \multicolumn{3}{|c|}{128} & \multicolumn{2}{|c|}{111} & 88 \\
\hline $\mathrm{E}_{2} / \mathrm{kJ} \mathrm{mol}^{-1}$ & \multicolumn{2}{|c|}{133} & \multicolumn{3}{|c|}{128} & \multicolumn{2}{|c|}{137} & 152 \\
\hline $\mathrm{E}_{3} / \mathrm{kJ} \mathrm{mol}^{-1}$ & \multicolumn{2}{|c|}{142} & \multicolumn{3}{|c|}{151} & \multicolumn{2}{|c|}{151} & 144 \\
\hline $\log _{10} A_{1} / \mathbf{s}^{-1}$ & 6.71 & 6.52 & 9.08 & 8.93 & 9.02 & 6.85 & 6.71 & 4.35 \\
\hline $\log _{10} A_{2} / s^{-1}$ & 7.83 & 7.46 & 7.89 & 7.78 & 7.82 & 8.10 & 7.98 & 8.23 \\
\hline $\log _{10} A_{3} / s^{-1}$ & 8.54 & 8.11 & 9.08 & 8.91 & 8.88 & 9.07 & 8.88 & 7.11 \\
\hline $\mathbf{b}_{2}$ & 0.35 & 0.17 & 1.31 & 1.22 & 1.31 & 0.41 & 0.69 & 0.92 \\
\hline $\mathbf{b}_{3}$ & 1.21 & 0.56 & 0.68 & 0.78 & 0.69 & 0.82 & 0.93 & 1.02 \\
\hline $\mathbf{a} 2$ & 0.19 & 0 & 0 & 0 & 0 & 0 & 0.69 & 0 \\
\hline a3 & 5.09 & 3.27 & 2.52 & 2.64 & 2.07 & 3.72 & 2.91 & 0 \\
\hline $\mathbf{z}_{2}$ & 1.24 & - & - & - & - & - & 0.78 & - \\
\hline $\mathbf{z 3}$ & 0.79 & 1.39 & 0.87 & 1.03 & 0.99 & 0.83 & 0.85 & - \\
\hline $\mathbf{f}_{2}(\mathbf{0})$ & 1 & 1 & 1 & 1 & 1 & 1 & 1.0 & 1 \\
\hline$\alpha_{2, \max }$ & 0 & 0 & 0 & 0 & 0 & 0 & 0.11 & 0 \\
\hline $\mathbf{f}_{3}(\mathbf{0})$ & 0.2 & 0.5 & 0.5 & 0.6 & 0.7 & 0.3 & 0.5 & 1 \\
\hline$\alpha_{3, \max }$ & 0.66 & 0.65 & 0.60 & 0.54 & 0.50 & 0.67 & 0.55 & 0.00 \\
\hline$q_{1}$ & \multicolumn{2}{|c|}{0.61} & & \multicolumn{2}{|l|}{0.91} & \multicolumn{2}{|c|}{0.63} & 0.22 \\
\hline $\mathbf{q}_{2}$ & \multicolumn{2}{|c|}{0.67} & & \multicolumn{2}{|l|}{0.65} & \multicolumn{2}{|c|}{0.70} & 0.65 \\
\hline$q_{3}$ & \multicolumn{2}{|c|}{0.59} & & \multicolumn{2}{|l|}{0.56} & \multicolumn{2}{|c|}{0.53} & 0.85 \\
\hline $\mathbf{c}_{1}$ & \multicolumn{2}{|c|}{0.07} & & \multicolumn{2}{|l|}{0.06} & \multicolumn{2}{|c|}{0.10} & 0.15 \\
\hline $\mathbf{c}_{2}$ & \multicolumn{2}{|c|}{0.39} & & \multicolumn{2}{|l|}{0.27} & \multicolumn{2}{|c|}{0.30} & 0.56 \\
\hline $\mathbf{c}_{3}$ & \multicolumn{2}{|c|}{0.44} & & \multicolumn{2}{|l|}{0.62} & \multicolumn{2}{|c|}{0.47} & 0.24 \\
\hline
\end{tabular}

${ }^{\text {a }}$ The partial reactions are visualized in Figures 2 and 3 where line styles,,$+++ \ldots$ and - . - belong to partial reactions 1,2 and 3 , respectively.

${ }^{b}$ An $f_{j}\left(\alpha_{j}\right)$ function is characterized by its initial value, $f_{j}(0)$, and the position of its maximum, $\alpha_{\max , j}$. Since $\mathrm{f}_{1}\left(\alpha_{1}\right)$ was approximated by first order reaction, its characteristics are not listed.

${ }^{\mathrm{c}}$ The kinetic parameters of the demineralized sample belong to both particle sizes studied.

${ }^{\mathrm{d}}$ The fit values were calculated for the given subgroup by eq. 9 , as described in the text.

The fit and the partial curves are shown in Figures 2 and 3 for the experiments carried out in pure oxygen at particle sizes $9-11 \mu \mathrm{m}$. Figure 2 illustrates the shape and position of the partial curves at a constant heating rate. The difference between the untreated and the partially demineralized samples is noticeable. The devolatilization reaction (curve ++++ ) is similar for all chars. (Note that each experiment has its own scales in Figures 2 and 3, as indicated on the axes, for a better visibility.) The relatively low activation energy for the devolatilization reflects the formal approximation of several elementary processes. An earlier work shows that distributed activated energy models (DAEM) give a more versatile description for charcoal devolatilization $^{24}$, but it was out of the scope of the present work. The burn-off reactions, however, occur in a much lower temperature domain in the experiments with untreated charcoals. This behavior is especially remarkable if we consider that the partially demineralized charcoal has much higher internal surfaces than its 
untreated counterpart, $\left(58 \mathrm{~m}^{2} / \mathrm{g}\right.$ vs. $\left.9 \mathrm{~m}^{2} / \mathrm{g}\right)$. The difference reflects the importance of the well-known catalytic activity of the acid-soluble minerals. ${ }^{17-18,25-26}$ In an earlier work, Iniesta et al. ${ }^{25}$ pointed out that the inorganic ions have a higher influence on the char reactivity than the surface area does. They also observed that the acid washing of the feedstock considerably reduces the reactivity of the produced char. ${ }^{26}$ The high specific surface of the partially demineralized charcoal in the present work explains why the reactivity of this sample was not influenced by the grinding that usually increases only the external surface. For the untreated charcoal the activation energies of the two burn-off reactions are similar: $E_{2}$ varies between $128-137 \mathrm{~kJ} / \mathrm{mol}$ and $E_{3}$ varies between $142-151 \mathrm{~kJ} / \mathrm{mol}$. Note that an activation energy variation in $9 \mathrm{~kJ} / \mathrm{mol}$ intervals is small if compared to the uncertainties arising from various experimental errors. ${ }^{27}$ This observation suggests that the chemical reactions are similar in the three untreated charcoal samples. (The possible reasons for the different behavior of these samples will be discussed later in the text, when the obtained $f_{2}\left(\alpha_{2}\right)$ functions will be presented). It is possible to model the experiments by neglecting the variations in the $E_{2}$ and $E_{3}$ values. In a test evaluation, all the 28 experiments with untreated charcoals were evaluated simultaneously, looking for $E_{1}, E_{2}$ and $E_{3}$ values optimal for all the three charcoals, while the rest of the variables were allowed to vary according to the considerations outlined in paragraph 4.1. This procedure resulted in a somewhat worse overall fit; the root-mean-square fit calculated for the 28 untreated charcoal experiments by eq. 9 went up from 3.4 to $4.0 \%$. The poorest fit was obtained for the experiments with top fraction charcoal. The resulting activation energy values were $E_{1}=117, E_{2}=133$ and $E_{3}=150 \mathrm{~kJ} / \mathrm{mol}$.

Figure 2 shows that the burn-off of the partially demineralized charcoal occurs at higher temperatures than in the untreated charcoals. The difference is especially pronounced in the ending temperatures of the burnoff. In thermal analysis, the ending temperature of a process is usually characterized by the extrapolated offset temperature of the experimental $-\mathrm{dm} / \mathrm{dt}$ curve, where the extrapolation is carried out from the steepest part of the decay section..$^{13}$ At $5^{\circ} \mathrm{C} / \mathrm{min}$, in pure oxygen the extrapolated offset temperatures of the untreated charcoals varied between 414 and $431^{\circ} \mathrm{C}$. The same value was $555-558^{\circ} \mathrm{C}$ in the case of the partially demineralized charcoal. The difference between the mean offset values of the untreated and partially demineralized charcoals was $126^{\circ} \mathrm{C}$. This difference was even higher, around $160^{\circ} \mathrm{C}$ in $20 \% \mathrm{O}_{2}$, at $20^{\circ} \mathrm{C} / \mathrm{min}$ heating rate.

In the case of the untreated charcoals, the formal reaction order on the oxygen concentration varied between 0.5 and 0.9. The oxygen concentration had the highest and lowest effect on the devolatilization reaction and on the last burn-off step respectively ( $\mathrm{q}_{1}$ varied between 0.6 and 0.9 while $\mathrm{q}_{3}$ was $0.5-0.6$ ). An opposite tendency was observed in the case of the partially demineralized charcoal, where $\mathrm{q}_{1}$ was 0.2 and $\mathrm{q}_{3}$ was 0.9 .

The $c_{j}$ coefficients express the normalized mass losses belonging to the partial reactions. Since the first partial process was due to an oxidative devolatilization, we compared the $c_{1}$ values to the devolatilization without the presence of oxygen in the temperature domains of the $1^{\text {st }}$ reaction. TG experiments were carried out in inert gas flow at $20^{\circ} \mathrm{C} / \mathrm{min}$ heating rate, and normalized mass loss values were taken in the domains of the $1^{\text {st }}$ reaction in $20 \%$ oxygen at $20^{\circ} \mathrm{C} / \mathrm{min}$ heating rate. Values $0.02,0.05,0.04$ and 0.06 were observed for 
Várhegyi et al., Combustion kinetics of corncob charcoals, Page 12 of 19

chars Top, Mid, Bot and Dem, respectively, while the corresponding $c_{1}$ values in Table 4 are $0.07,0.06,0.10$ and 0.15 . The differences can be due to the participation of the oxygen in the devolatilization.

It is difficult to compare the obtained kinetic parameters to the values published in the literature. The model employed here has common features with the 3-step model of Branca and Di Blasi. ${ }^{18}$ However, their experimental setup was very different from the present one, they used large samples and radiative heating. Still there is some similarity in the activation energies in the two works: the devolatilization steps had relatively low E values, while the char burn-off could be described by higher E values in both cases. There is a closer match between the present paper and our earlier work on char reactivity that was carried out with similar experimental conditions and chars. ${ }^{14}$ In that work charcoals prepared from macadamia nutshell and eucalyptus wood (Eucalyptus grandis) were investigated by a 2-step model. 105-110 kJ/mol activation energies were obtained for the devolatilization and 146-148 kJ/mol for the char burn-off. ${ }^{14}$ In an earlier work, semi-cokes were investigated. ${ }^{11}$ There was no devolatilization step due to the high preparation temperature of those samples. Two burn-off reactions were observed of which the one closer to the temperature domain of the present work revealed similar activation energy, $135-147 \mathrm{~kJ} / \mathrm{mol}$.

Figure 3 illustrates how the information content of the experiments is increased by involving stepwise experiments. The partial curves have relatively simple shapes at linear heating programs (as Figure 2 shows) but the employed evaluation method forces the model to describe the much more complex experiments seen in Figure 3, too. 
Várhegyi et al., Combustion kinetics of corncob charcoals, Page 13 of 19
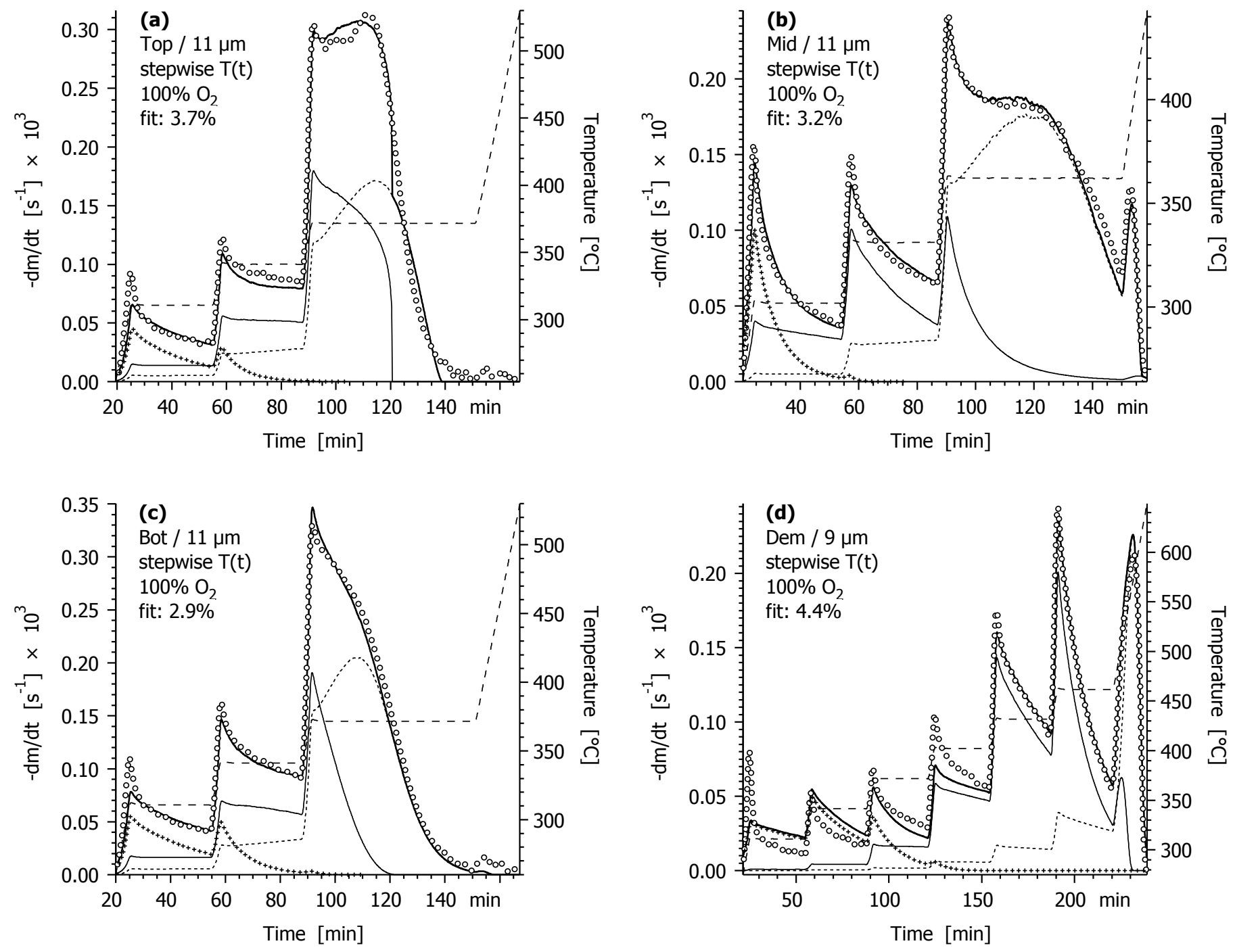

Figure 3. Experimental curves (o o o), temperature programs (-- -), simulated curves (-) and partial curves $(+++, \ldots,-\ldots)$ belonging to $100 \% \mathrm{O}_{2}$ and stepwise heating. (See also the caption of Figure 2.)
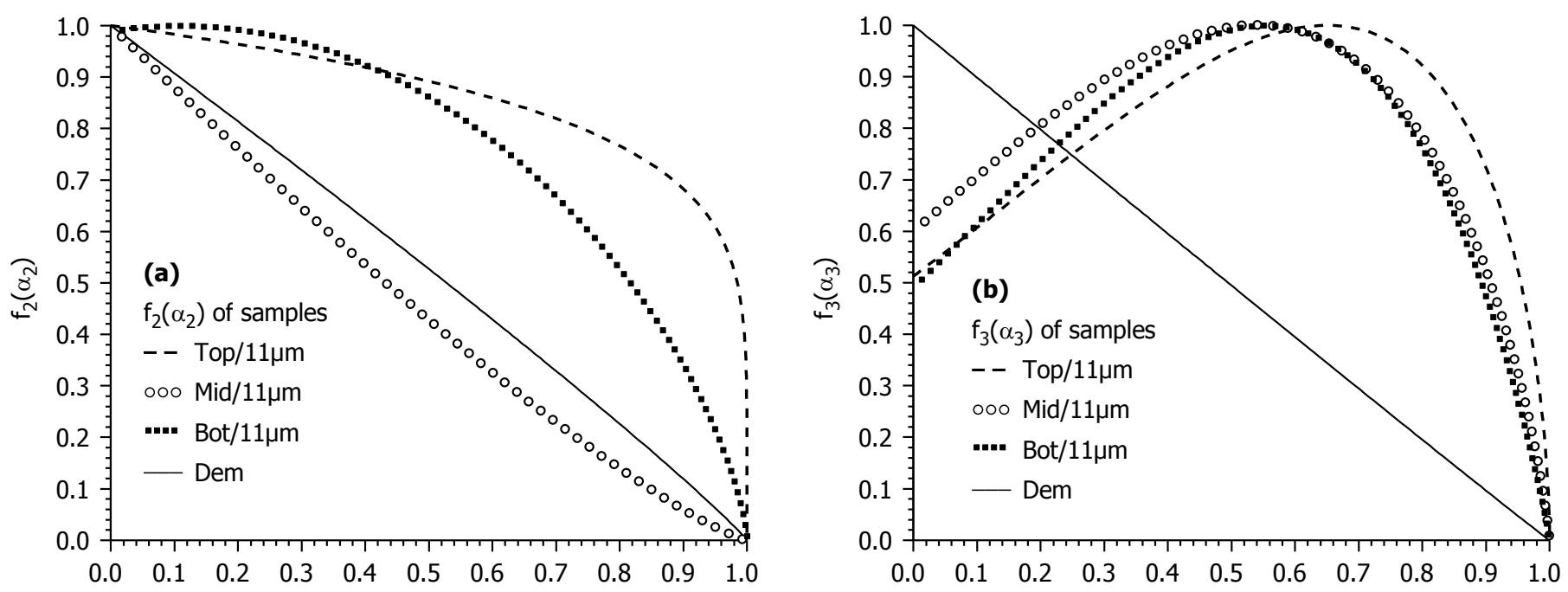

Figure 4. $f_{j}\left(\alpha_{j}\right)$ functions of the burn-off reactions for selected samples.

Figure 4 displays the $f_{2}\left(\alpha_{2}\right)$ and $f_{3}\left(\alpha_{3}\right)$ functions belonging to Figures 2 and 3. (Functions $f_{1}\left(\alpha_{1}\right) \equiv 1-\alpha_{1}$ were not plotted.) Both $f_{2}\left(\alpha_{2}\right)$ and $f_{3}\left(\alpha_{3}\right)$ of the partially demineralized charcoal and the $f_{2}\left(\alpha_{2}\right)$ of the untreated 
middle section charcoal exhibited a nearly first order kinetics. (See curves — and o o o in panel a of Figure 4.) This probably means that the accelerating and decelerating factors compensate each other during the burn-off. The rest of the curves are markedly concave. The $f_{3}\left(\alpha_{3}\right)$ functions of the untreated charcoals in panel $\mathbf{b}$ are similar to the ones deduced from the random pore models ${ }^{19-22}$ reflecting that the growth of the internal pores increases the available reaction surface area and its accessibility during the burn-off. After reaching a maximum, this effect is counterbalanced by the consumption of the sample. The $f_{2}\left(\alpha_{2}\right)$ functions did not evidence such a pronounced effect of the internal pores . As mentioned above, the untreated middle section sample exhibited kinetics not far from the characteristics of a first order process (with $b_{2}=1.22-1.31$ ). The top and bottom section samples exhibited $\mathrm{f}_{2}\left(\alpha_{2}\right)$ functions that are similar to the ones deduced for reactions occurring on the external surface of the particles with $b_{2}$ values varying from 0.17 (nearly zero order) to 0.69 (nearly a contracting sphere model). These observations suggest that pseudo-components 2 and 3 of the model correspond to particles/fragments of different properties in the charcoal. The marked variation of the $f_{2}\left(\alpha_{2}\right)$ functions indicate that the inhomogeneities in the charcoal reactor influence highly the properties of the $2^{\text {nd }}$ pseudocomponent. Note that the Flash Carbonization is a complex process including solid phase carbonization as well as the forming of charcoal from the liquid (tar) fraction. Accordingly, one can expect the formation of different structures in its products. However, the detailed investigation of the microstructure of the flash carbonization charcoal was out of the scopes of the present work; it is scheduled for a later study.

4.3 A test evaluation with less adjustable parameters. In the approach outlined above, the 28 experiments with untreated charcoals were described by 90 adjustable parameters, leaving an average of 3.25 unknowns for an experiment. A relatively lower amount of unknowns, 1.8 parameters per experiment was determined for the partially demineralized charcoal due to reasons outlined earlier. In a test evaluation we checked how the experiments with untreated charcoals can be modeled if fewer parameters are allowed to describe the differences between the properties of the untreated samples. In this evaluation, the 28 experiments with untreated charcoals were evaluated simultaneously, assuming identical $E_{j}, q_{j}$, and $f_{j}\left(\alpha_{j}\right)$ parameters for all untreated samples. The reactivity differences were described by the $A_{j}$ values, allowing them to depend both on the charcoal properties (reactor section) and on the grinding. The $c_{j}$ parameters were allowed to depend on the reactor section to express the different composition of the samples. In this way we obtained a common set of $E_{j}, q_{j}$, and $\mathrm{f}_{\mathrm{j}}\left(\alpha_{\mathrm{j}}\right)$ parameters for all untreated charcoal experiments, separate $\mathrm{c}_{\mathrm{j}}$ values for the top, middle and bottom section samples, and a separate set of $A_{j}$ for each charcoal at each grinding level. Altogether we had 42 unknown parameters for the 28 experiments, resulting in an average of 1.5 unknowns per experiment. In this evaluation the root-mean-square fit (calculated for the 28 untreated charcoal experiments by eq. 9) went up from 3.4 to $5.2 \%$. Besides the worse fit, visible alterations (artifacts) appeared in the shapes of the calculated -dm/dt curves. Accordingly, we regard this evaluation only as a test on the occurrence of the main features of the earlier results in a rougher approximation, too. The activation energies were found to be $E_{1}=108, E_{2}=133$ and $E_{3}=149 \mathrm{~kJ} / \mathrm{mol}$, in accordance with the results outlined earlier. The $\mathrm{q}_{\mathrm{j}}$ values were around 0.6. The $f_{2}\left(\alpha_{2}\right)$ and $f_{3}\left(\alpha_{3}\right)$ functions are shown in Figure 5. They exhibit the same, 
peculiar differences as the ones in Figure 4: $f_{2}\left(\alpha_{2}\right)$ had features characteristic to external-surface reactions while $f_{3}\left(\alpha_{3}\right)$ reflects the importance of the internal pores in the burn-off. Accordingly, this test evaluation shows that the main reaction kinetic findings of our work, including the magnitudes of activation energies and the peculiar difference between the character of the $f_{2}\left(\alpha_{2}\right)$ and $f_{3}(\alpha)$ functions cannot be due to a mathematical ill-definition caused by the high number of adjustable parameters.

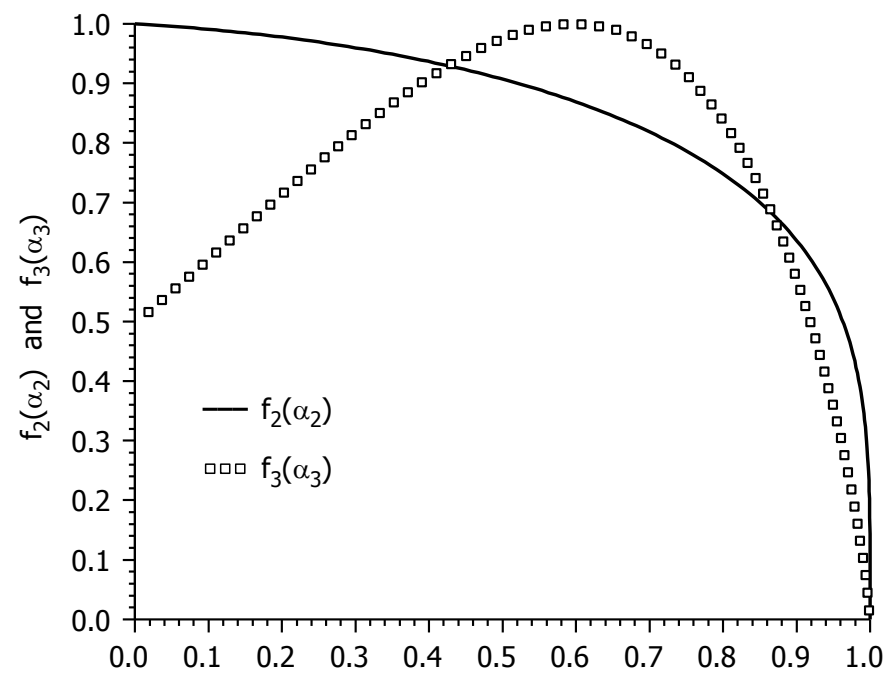

Figure 5. $\mathrm{f}_{2}\left(\alpha_{2}\right)$ and $\mathrm{f}_{3}\left(\alpha_{3}\right)$ obtained for all untreated samples in the test evaluation described in paragraph 4.3 .

4.4 Test evaluation with power law approximations for $f_{j}\left(\alpha_{j}\right)$. Earlier investigators ${ }^{16-18}$ employed simple power law kinetic models in charcoal studies, as described above, in paragraph 3.1. We tested the performance of the power law model, too. In our case it is equivalent to setting $a_{j}=0$ in eq. 6 , resulting in

$$
f_{j}\left(\alpha_{j}\right)=\left(1-\alpha_{j}\right)^{b_{j}}
$$

The evaluation scheme outlined in paragraph 4.1 was employed here, too. Note that $a_{l}$ was 0 in all calculations of this paper, while the $a_{2}=a_{3}=0$ assumption coincided with the optimal $a_{j}$ values for the demineralized sample. Accordingly, only the untreated samples were reevaluated by taking out $a_{2}, a_{3}, z_{2}$, and $z_{3}$ from the set of adjustable parameters. In this way the number of adjustable parameters for the top, middle and bottom fraction charcoals went down from 27, 36, and 27 to 19, 24, and 19, respectively. These values correspond to a relative decrease of $30-33 \%$. The obtained fits, however, were much worse than in the unconstrained case, as the comparison of Figures 6 and 2 shows. The least squares sum (eq. 8) increased by a factor of about 2.6 for all the three untreated charcoals. Besides, formula (10) cannot mimic the selfaccelerations that may appear during char burn-off due to the reaction on the pore surfaces. This behavior can be well noticed by comparing Figure 7 to panel $b$ of Figure 4 . The poor fit provided by the power law model underline the importance of finding proper $f(\alpha)$ functions in char studies. 
Várhegyi et al., Combustion kinetics of corncob charcoals, Page 16 of 19
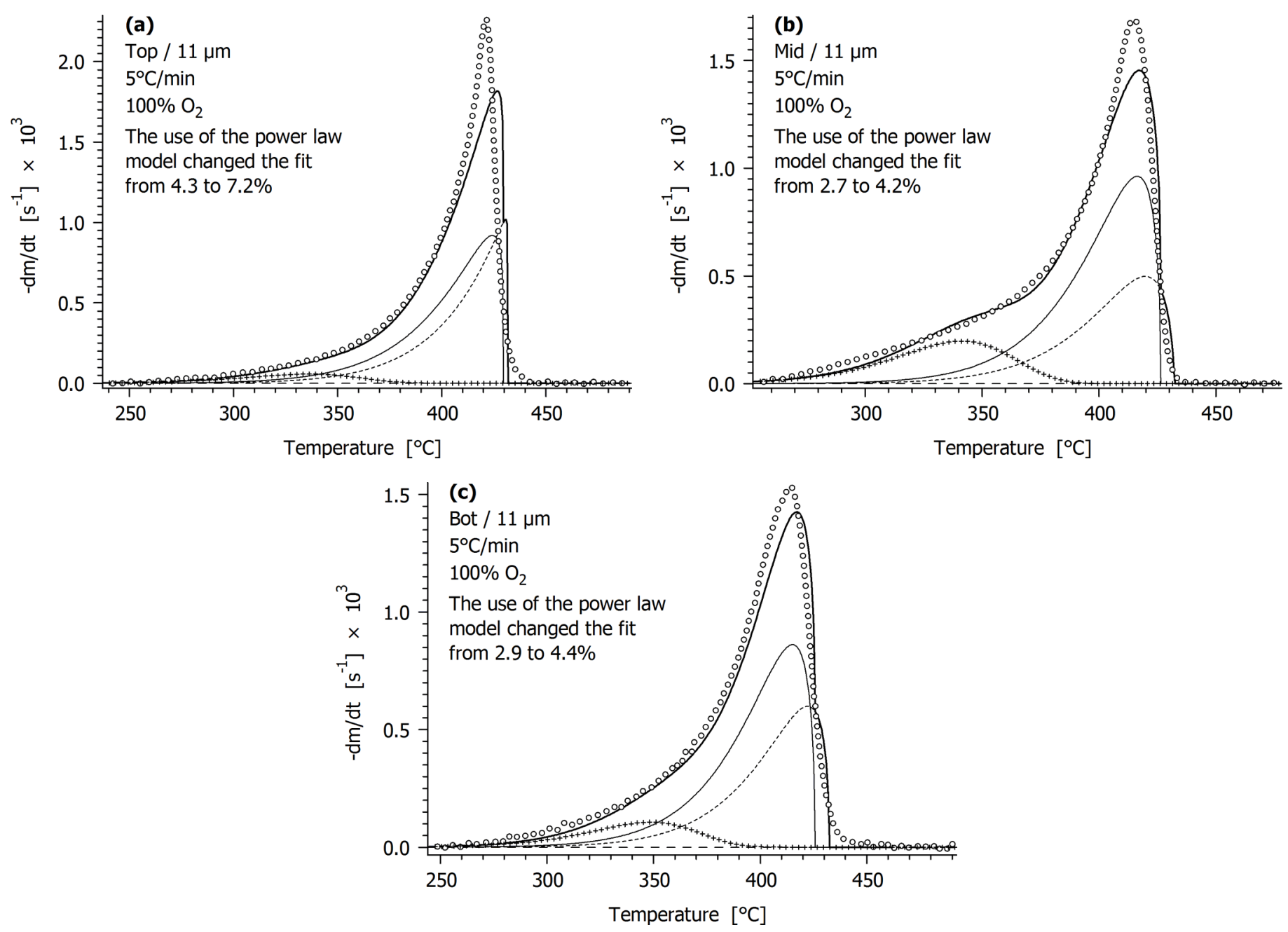

Figure 6. Evaluation by the power law kinetic model. (See Figure 2 for comparison.)

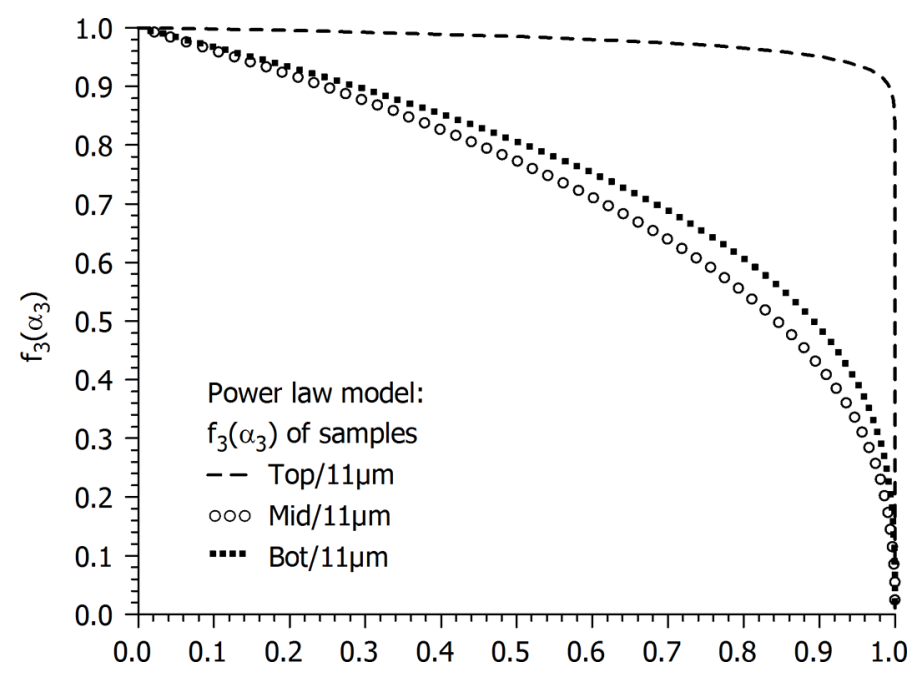

Figure 7. $f_{3}\left(\alpha_{3}\right)$ functions obtained from the evaluation by the power law kinetic model. (See panel $\mathbf{b}$ of Figure 4 for comparison.).

\section{Conclusions.}

(1) The combustion properties of charcoals produced by a modern, efficient method were studied in the kinetic regime, at oxygen partial pressures of 0.2 and 1 bar. Relatively small differences were observed between the samples arising from the different sections of the reactor. The level of grinding considerably affected the reactivity. A partial removal of the minerals from the feedstock (corncobs) by an acid-washing 
procedure resulted in ca. 6 times higher specific surface in the charcoal. The burn-off of this partially demineralized char was not affected by the grinding at all. In spite of the higher surface area, the partially demineralized charcoal has evidenced a much lower reactivity. In the linear heating rate experiments the burn-off terminated ca. $130-160^{\circ} \mathrm{C}$ higher than in corresponding experiments with untreated chars.

(2) Contrary to the special carbons prepared from high purity chemical substances, a real biomass charcoal has chemical, structural and physical inhomogeneities and contains minerals. Accordingly, its combustion is a complex process that cannot be described by a single reaction. In the present work a model based on a devolatilization step and two burn-off reactions gave an adequate description over a wide range of experimental conditions within the kinetic regime.

(3) 38 experiments on 4 charcoal samples were evaluated. The experiments differed in their temperature programs, in the ambient gas composition and in the grinding of the samples. This procedure increased the amount of information available, made possible the determination of a relatively large number of unknown parameters and ensured that the model described a wide range of observations. Considerations were outlined to decide which parameters should be identical in all experiments on a given charcoal and which parameters should be allowed to depend on the grinding level.

(4) On this base, characteristics of the combustion process were determined, including activation energy values characteristic for the temperature dependence of the burn-off; formal reaction orders characterizing the dependence on the oxygen content of the ambient; and $f_{j}\left(\alpha_{j}\right)$ functions describing the conversion dependence of the partial processes. The parameters of the model have shown a moderate dependence on the properties of the charcoal. In the case of the untreated charcoals, part of the parameters depended on the level of grinding, too.

Acknowledgement. We thank the following sponsors of our work for their support: The Consortium on Plant Biotechnology Research, the Office of Naval Research, Pacific Carbon and Graphite, LLC; the Coral Industries Endowment of the University of Hawaii, and the University of Hawaii. The work in Hungary was supported by the Hungarian National Research Fund (OTKA T37705 and T37704). The authors are grateful to Mr. Ferenc Till for his help.

\section{NOMENCLATURE}

$\alpha \quad$ reacted fraction of a pseudocomponent

a parameter of $f(\alpha)$ in eq. 6

A pre-exponential factor $\left(\mathrm{s}^{-1}\right)$

$\mathrm{A}_{\mathrm{q}}$ the pre-exponential factor of eq. (1) which is not used in the present paper due to its variable dimension, $\mathrm{s}^{-1} \mathrm{MPa}^{-\mathrm{q}}$

b parameter of $f(\alpha)$ in eq. 6

c normalized mass of volatiles formed from a pseudocomponent 
$\mathrm{C}_{2}$ relative concentration $(\mathrm{V} / \mathrm{V})$ of the oxygen in the ambient gas flow

E activation energy $(\mathrm{kJ} / \mathrm{mol})$

$f(\alpha)$ a function expressing the dependence of the reaction rate on the conversion

fit $100 \mathrm{~S}^{0.5}(\%)$

h height of a -dmobs/dt curve

m normalized sample mass (dimensionless)

$\mathrm{m}^{\text {calc }}(\mathrm{t}) \quad$ normalized sample mass calculated from a model

$\mathrm{m}^{\mathrm{obs}}(\mathrm{t}) \quad$ mass of the sample divided by the initial sample mass

M number of pseudocomponents

$\mathrm{q}$ formal reaction rate on $\mathrm{P}_{\mathrm{O}_{2}}$ and $\mathrm{C}_{2}$ in equations 1 and 6 , respectively

$N_{\exp }$ number of experiments evaluated simultaneously

$\mathrm{N}_{\mathrm{k}} \quad$ number of evaluated data on the $k$ th experimental curve

$\mathrm{P}_{2}$ partial pressure of oxygen $(\mathrm{kPa})$

$\mathrm{R}$ gas constant $\left(8.3143 \times 10^{-3} \mathrm{~kJ} \mathrm{~mol}^{-1} \mathrm{~K}^{-1}\right)$

$\mathrm{s}, \mathrm{s}_{0}$ reactive surface and its initial value

$\mathrm{S}$ least squares sum

$\mathrm{t} \quad$ time $(\mathrm{s})$

$\mathrm{T}$ temperature $\left({ }^{\circ} \mathrm{C}, \mathrm{K}\right)$

$\mathrm{z} \quad$ parameter of $\mathrm{f}(\alpha)$ in eq. 6

Subscripts:

i digitized point on an experimental curve

j pseudocomponent

$\mathrm{k}$ experiment

\section{Literature cited}

(1) Morrison, L. H. The Coal Dust Engine Details of the Design. Power 1928, 68, 746.

(2) Pawlikowski, R. The Coal Dust Engine Upsets Tradition. Power 1928, 68, 136.

(3) McMillian, M. H.; Webb, H. A. Coal-Fueled Diesels: Systems Development. In Coal Fired Diesel Engines; M. H. McMillian and H. A. Webb, Eds.; ASME: New York, 1988; p 1.

(4) Bell, S. R.; Choi, G. H. Parametric Studies on a Coal-Fueled Diesel Engine. Comb. Sci. Tech. 1994, 96, 85 .

(5) McMillen, D. F.; Webb, H. A., Ed., Coal-Fueled Diesel Engines, ASME: New York, 1988.

(6) Kamei, K., personal communication, 2003.

(7) Antal, M. J.; Allen, S. G.; Dai, X.; Shimizu, B.; Tam, M. S.; Grønli, M. G. Attainment of the Theoretical Yield of Carbon from Biomass. Ind. Eng. Chem. Res. 2000, 39, 4024.

(8) Antal, M. J.; Grønli, M. G. The Art, Science, and Technology of Charcoal Production. Ind. Eng. Chem. Res. 2003, 42, 1919.

(9) Antal, M. J.; Mochidzuki, K.; Paredes, L. S. Flash Carbonization of Biomass. Ind. Eng. Chem. Res. 2003, 42,3690 . 
(10) Nunoura, T.; Wade, S. R.; Bourke, J. P.; Antal, M. J., Jr. Studies of the Flash Carbonization Process. 1. Propagation of the Flaming Pyrolysis Reaction and Performance of a Catalytic Afterburner Ind. Eng. Chem. Res. 2006, 45, 585.

(11) Várhegyi, G.; Szabó, P.; Jakab, E.; Till, F.; Richard J-R. Mathematical Modeling of Char Reactivity in $\mathrm{Ar}-\mathrm{O}_{2}$ and $\mathrm{CO}_{2}-\mathrm{O}_{2}$ Mixtures. Energy Fuels 1996, 10, 1208.

(12) Várhegyi, G.; Szabó, P.; Jakab, E.; Till, F. Least Squares Criteria for the Kinetic Evaluation of Thermoanalytical Experiments. Examples from a Char Reactivity Study. J. Anal. Appl. Pyrolysis 2001, 57, 203.

(13) Mészáros, E.; Várhegyi, G.; Jakab, E.; Marosvölgyi, B. Thermogravimetric and Reaction Kinetic Analysis of Biomass Samples from an Energy Plantation. Energy Fuels 2004, 18, 497.

(14) Várhegyi, G.; Szabó, P.; Antal, M. J., Jr.; Dai, X. Kinetic Modeling of the Gasification of Biomass Charcoals. In 1st World Conference on Biomass for Energy and Industry (Proceedings), Edited by S. Kyritsis et al., Volume 2, pp. 1783-1785, James \& James Science Ltd., 2001.

(15) Shafizadeh, F.; Sekiguchi, Y. Oxidation of Chars During Smoldering Combustion of Cellulosic Materials. Combust. Flame 1984, 55, 171.

(16) Janse, A. M. C.; de Jonge, H. G.; Prins, W.; van Swaaij, W. P. M. The Combustion Kinetics of Char Obtained by Flash Pyrolysis of Pine Wood. Ind. Eng. Chem. Res. 1998, 37, 3909.

(17) Di Blasi, C.; Buonanno, F.; Branca, C. Reactivities of Some Biomass Chars in Air. Carbon 1999, 37, 1227.

(18) C. Branca, C. Di Blasi: Global Kinetics of Wood Char Devolatilization and Combustion. Energy Fuels 2003, 17, 1609.

(19) Bhatia; S. K; Perlmutter, D. D. A Random Pore Model for Fluid-Solid Reactions: I. Isothermal Kinetic Control. AIChE J. 1980, 26, 379.

(20) Gavalas, G. R. A Random Capillary Model With Application to Char Gasification at Chemically Controlled Rates. AIChE J. 1980, 26, 577.

(21) Reyes, S.; Jensen, K. F. Percolation Concepts in Modeling of Gas-Solid Reactions. I. Application to Char Gasification in the Kinetic Regime. Chem. Eng. Sci. 1986, 41, 333.

(22) Tseng, H. P.; Edgar, T. F. The Change of the Physical-Properties of Coal Char During Reaction. Fuel 1989, 68, 114.

(23) Várhegyi, G.; Pöppl, L.; Földvári, I. Kinetics of the Oxidation of Bismuth Tellurite, $\mathrm{Bi}_{2} \mathrm{TeO}_{5}$ : Empirical Model and Least Squares Evaluation Strategies to Obtain Reliable Kinetic Information. Thermochim. Acta 2003, 399, 225.

(24) Várhegyi, G.; Szabó, P.; Antal, M. J., Jr. Kinetics of Charcoal Devolatilization. Energy Fuels 2002, 16, 724.

(25) Iniesta E.; Sánchez, F.; García, A.; Marcilla, A. Influence of the Holding Temperature of The First Heating Step in a Two-Heating Step Carbonisation Process on The Properties of Chars And Activated Carbons From Almond Shells. J. Anal. Appl. Pyrolysis, 2001, 58-59, 967.

(26) Iniesta E.; Sánchez, F.; García, A.; Marcilla, A. Yields and $\mathrm{CO}_{2}$ Reactivity of Chars From Almond Shells Obtained by a Two Heating Step Carbonisation Rocess. Effect of Different Chemical Pre-Treatments and Ash Content. J. Anal. Appl. Pyrolysis, 2001, 58-59, 983.

(27) Grønli, M.; Antal, M. J., Jr.; Várhegyi, G. A Round-Robin Study of Cellulose pyrolysis Kinetics by Thermogravimetry. Ind. Eng. Chem. Res. 1999, 38, 2238. 